\title{
Cellular-Mesenchymal to Epithelial Transition Factor Upregulates Aquaporin 3 Expression in Human Breast Cancer Cells
}

\section{Fanshuang Zhu}

Taizhou Hospital of Zhejiang Province

Lijie Chen

Taizhou Hospital of Zhejiang Province

Yixing Zhou

Taizhou Hospital of Zhejiang Province

Jiaxiang An

Taizhou Hospital of Zhejiang Province

\section{Zenggui Wu}

Taizhou Hospital of Zhejiang Province

Jinxi Hu

Taizhou Hospital of Zhejiang Province

\section{Zhaosheng Ma}

Taizhou Hospital of Zhejiang Province

Feilin Cao ( $\nabla$ caofl1263@163.com )

Taizhou Hospital of Zhejiang Province https://orcid.org/0000-0002-4458-9692

\section{Research}

Keywords:

Posted Date: May 1st, 2020

DOI: https://doi.org/10.21203/rs.3.rs-24717/v1

License: (1) (1) This work is licensed under a Creative Commons Attribution 4.0 International License. Read Full License 


\section{Abstract \\ Background}

Aquaporin 3 (AQP3) and Cellular-mesenchymal to epithelial transition factor (c-Met) are both overexpressed in human breast cancer and highly related to proliferation and migration. However, it is still unclear whether c-Met is associated with AQP3. The study objective was to explore the relationship between c-Met and AQP3 in human breast cancer.

\section{Methods}

We used immunohistochemistry to determine the expression of AQP3 and c-Met in breast cancer tissue specimens and analysed whether there was any correlation between the two molecules. Real-time quantitative polymerase chain reaction and Western blotting were used to detect AQP3 expression in MCF-7 and MDA-MB-231 cells after human hepatocyte growth factor (hHGF) treatment and/or transfection with c-Met silencing small interfering (si)RNA. Additionally, cell migration was examined with a wound scratch assay.

\section{Results}

Based on the immunohistochemical results combined with the clinicopathological data of 59 breast cancer patients, c-Met exhibited a significant correlation with AQP3 in breast cancer tissue. Studies have shown that hHGF can increase c-Met phosphorylation, and we discovered that the hHGF-induced increase in AQP3 expression was dose dependent. However, after reducing c-Met expression with c-Met-specific siRNA, AQP3 expression decreased accordingly. Additionally, the wound scratch assay showed that AQP3-specific siRNA or c-Met-specific siRNA significantly inhibited breast cancer cell migration, which was promoted by hHGF.

\section{Conclusions}

Our study indicated that AQP3 expression was regulated by c-Met in human breast cancer. These discoveries may help us comprehend the mechanisms underlying breast cancer development and invasion and offer another possibility for targeted treatment of breast cancer.

\section{Introduction}

Breast cancer is the most common female malignancy. In 2018, there were 2.1 million new cases of breast cancer in women worldwide. Despite standardized multidisciplinary treatments, the recurrence rate, metastasis rate, and drug resistance rate of breast cancer cannot be ignored (1). Therefore, 
understanding the mechanisms underlying the invasion, proliferation, and cell transfer of breast cancer and the discovery of new therapeutic molecular targets are extremely important.

c-Met is a receptor of hepatocyte growth factor (HGF). Noriega-Guerra $\mathrm{H}$ et al. (2) concluded that c-Met is related to the development and metastasis of a number of malignancies, including breast cancer. c-Met binds to HGF, resulting in the autophosphorylation and overexpression of c-Met, and this interaction participates in embryonic development, wound repair, tissue regeneration, cell differentiation, etc. under physiological conditions but promotes the proliferation, invasion, migration, antiapoptotic processes, and angiogenesis of cancer cells under pathological conditions (2). High HGF/c-Met signalling promotes breast cancer progression (3), and the activation of c-Met leads to phosphorylation of its downstream proteins (mainly gab1, followed by gab2), followed by the activation of signal transduction proteins such as PI3K, FAK, JUN, ERK, and STATs (4-7). Thus, activation of c-Met in breast cancer can further activate PI3K and ERK.

Aquaporins (AQPs) are proteins located on the cell membrane. In mammals, the AQP family has 13 (AQP0-12) members, and they are closely related to the progression of human malignancies (8). AQP3, as a member of the AQP family, plays key roles in the development and progression of malignancies, such as breast cancer (9). In breast cancer tissue, AQP3 is overexpressed (10), and the expression level is closely related to the proliferation, invasion, and migration of breast cancer (11). Cao XC et al. (12) indicated that FGF-2 activated the ERK and/or PI3K signalling pathways to promote AQP3 expression. Thus, the expression of AQP3 can be increased by activating these two signalling pathways in breast cancer.

In conclusion, AQP3 and c-Met expression is increased in breast cancer, and the expression levels are positively related to proliferation, invasion, and migration. However, it is still unclear whether c-Met is related to AQP3. Recent studies have shown that the ERK and PI3K signalling pathways can be activated by the activation of c-Met in breast cancer. Another study has shown that activating the ERK and PI3K signalling pathways in breast cancer can lead to increased expression of AQP3. Therefore, we speculated that c-Met is connected to AQP3. In this study, our aim was to explore the relationship between c-Met and AQP3 expression in breast cancer.

\section{Methods}

\section{Tissue specimens}

All human breast cancer tissue specimens included in this study were obtained from 59 patients between July 2018 and July 2019 at Taizhou Hospital of Zhejiang Province. All patients were female and aged between 18 and 70 years old. The specimens were pathologically diagnosed as invasive ductal carcinoma of the breast according to the eighth edition of the American Joint Committee on Cancer (AJCC) standard. Patients who underwent any neoadjuvant treatments before surgery were not included in this study. In addition, this project received approval from the Ethics Committee of Taizhou Hospital of Zhejiang Province. We collected the specimens immediately after surgery and stored them in liquid 
nitrogen. The following clinicopathological features of these patients were collected: age ( $\geq 50$ years or < 50 years), menopausal status (premenopausal or postmenopausal), surgical approach (modified radical mastectomy or breast-conserving surgery), histological grade (I, II or III), pTNM stage (based on the eighth edition of the PTNM pathological staging system published by AJCC in 2018) (I, II or III), ER/PR/HER2/EGFR status (positive or negative), Ki-67 status (high expression: Ki-67 $\geq 14$ or low expression: Ki-67 $<13)$, tumour size $(\leq 2 \mathrm{~cm}$ or $>2 \mathrm{~cm}$ ), and lymph node status (positive: N1-N3 or negative: N0).

\section{Immunohistochemical detection of AQP3 and c-Met protein expression in cancer tissue specimens}

Breast cancer tissue specimens were embedded in paraffin after being fixed in phosphate-buffered formalin. Then, we cut the paraffin blocks into sections approximately $0.5 \mu \mathrm{m}$ thick, and the sections were detected by immunohistochemistry using standard $A B C$ peroxidase techniques. The following antibodies were used: AQP3 Rabbit Polyclonal Antibody (1:1,000; Abcam, Shanghai, China) and c-Met Rabbit Polyclonal Antibody (1:1000, Abcam). Immunohistochemical staining results were analysed by two senior pathologists independently. The scores for the AQP3 and c-Met proteins consisted of scores for the immunostaining intensity and stained area for the protein. The cell staining intensity was divided into four grades with a score range of 0-3: 0 (no colouration); 1 (weak colour intensity); 2 (moderate colour intensity); and 3 (strong colour intensity). The stained area of AQP3-positive cells was divided into five grades, with scores of $0-4: 0,0 \% ; 1,1 \%-10 \% ; 2,11 \%-50 \% ; 3,51 \%-80 \%$; and $4,>80 \%$ (13). The product of the final staining intensity score and the positive cell staining area score was considered the immunohistochemical staining score for the AQP3 protein. A score $>4$ was defined as high expression, and a score $\leq 4$ was defined as low expression. The stained area of c-Met-positive cells was also divided into five grades, with scores of $0-4: 0,0 \% ; 1,1 \%-24 \% ; 2,25 \%-49 \% ; 3,50 \%-74 \%$; and $4, \geq 75 \%$. The sum of the final staining intensity score and the positive cell staining area score was considered the immunohistochemical staining score for the protein; a score $>4$ was defined as high expression, and a score $\leq 4$ was defined as low expression.

\section{Cell culture}

We routinely cultured MCF-7 (Bioleaf Biotech, Shanghai, China) and MDA-MB-231 (Bioleaf Biotech) cells in high-glucose DMEM (Gibco, New York, USA) supplemented with $10 \%$ foetal bovine serum (Beyotime, Shanghai, China). The cells were cultured in a $5 \% \mathrm{CO}_{2}$ incubator at $37^{\circ} \mathrm{C}$.

\section{RNA interference and hHGF treatment}

Cells were seeded in 6-well plates with $2-3 \times 10^{5}$ cells per well and treated overnight. For an RNA interference assay, $20 \mu \mathrm{M}$ c-Met/AQP3-specific silencing small interfering (si)RNA or a negative control (NC) siRNA (Genepharma Biotech, Shanghai, China) was transfected into breast cancer cells using Lipofectamine $^{\mathrm{TM}} 3000$ (Invitrogen, Carlsbad, CA, USA), and the final siRNA concentration was $100 \mathrm{nM}$. The siRNA sequences used were shown in Table 1. For an hHGF (Yuduobio, Shanghai, China) treatment assay, different concentrations of $\operatorname{hHGF}(5,25$, or $50 \mathrm{ng} / \mathrm{ml})$ were added to cultures. 


\section{Real-time Quantitative polymerase chain reaction}

Total RNA was extracted from breast cells with TRIzol (Beyotime). cDNAs were synthesized using the 2 Step Real Time RT-PCR Kit (TAKARA, Dalian, China). Then, quantitative real-time polymerase chain reaction (RT-qPCR) was performed with the TB Green Premix Ex Taq Kit (TAKARA) using the Applied Biosystems 7500 Real-time PCR System. All primers used were synthesized by Sangon Biotech (Shanghai, China), and their sequences were shown in Table 2. This process was repeated more than three times for each sample in each experiment.

\section{Western blotting}

Ice-cold radioimmune precipitation assay (RIPA) buffer (Beyotime) mixed with phenylmethanesulfonyl fluoride (PMSF) (Beyotime) and phosphatase inhibitors (Applygen, Beijing, China) was used to lyse cells, and the cell lysates were evaluated with a BCA protein detection kit (Beyotime) to obtain the protein concentration. For immunoblotting, 10\% SDS-PAGE (Beyotime) was used to separate samples, and then we transferred sample strips to polyvinylidene fluoride (PVDF) membranes (Beyotime). After skim milk powder (Beyotime) was used for blocking for 1.5 hours, the membranes were incubated with primary and secondary antibodies in sequence. Then, the protein bands were visualized with an enhanced chemiluminescence (ECL) kit (Beyotime) and imaged with the ImageQuant LAS 500 Ultrasensitive Chemiluminescence Imager (GE Healthcare, Shanghai, China). The following antibodies were included: AQP3 Rabbit Polyclonal Antibody (1:1,000; Abcam), c-Met Rabbit Polyclonal Antibody (1:1000, Abcam), $\beta$ Actin Mouse Antibody (1:1,000; Beyotime), HRP Goat Anti-Rabbit IgG Antibody (1:4,000; Biosharp, Beijing, China), HRP Goat Anti-Mouse IgG Antibody (1:4,000; Biosharp).

\section{Wound scratch assay}

Breast cancer cells were seeded in 24-well plates and then given different treatments. After the cells became confluent, a straight scratch was created in the centre of each well using a 200- $\mu$ l pipette tip. Then, the cells were treated with low-serum medium and put back into the incubator for an incubation. Then, the scratch repopulation gap width was recorded by imaging (Optika XDS, Ponteranica, Italy) at 0 and 24 hours after treatment. The results of the wound scratch test are represented as the size of the cellfree area, which was quantified as the "average gap", and measured with ImageJ version 1.52a (Rawak Software, Stuttgart, Germany). The cell-free area at 0 hours was defined as $100 \%$, and the results of the assay at 24 hours were compared with the results at 0 hours.

\section{Statistical analysis}

All the statistical data were analysed by SPSS 24.0 statistical software (IBM Corp., Armonk, USA). Values are representative of more than three independent experiments and presented as the mean \pm standard error (SE). Clinicopathological results are expressed as percentages, and unpaired t-tests or the Pearson $\square^{2}$ test was used for comparisons between groups. The correlation between AQP3 and c-Met protein 
expression was analysed by Pearson correlation analysis. Data were compared among group by analysis of variance (ANOVA). $p<0.05$ was deemed to be statistically significant.

\section{Results}

\section{1. c-Met is strongly related to AQP3 in human breast cancer tissue}

This study used immunohistochemistry to evaluate AQP3 and c-Met protein expression in breast cancer tissue specimens from 59 breast cancer patients. The clinicopathological features of these patients are shown in Table 3. As shown in Table 3, AQP3 was overexpressed in $52.5 \%$ of the breast cancer tissue specimens (Fig. 1a and 1b), and this overexpression was significantly and positively related to age, tumour size and lymph node invasion ( $p=0.046, p=0.029, p=0.049, p=0.022$, and $p=0.020$ ). Furthermore, we found that $83.1 \%$ of the breast cancer tissue specimens exhibited c-Met overexpression (Fig. 1c and 1d), and the overexpression of c-Met showed significant positive relationships with tumour size and pTNM stage ( $p=0.002$ and $p<0.001$, respectively). No other variables were connected to AQP3 and c-Met expression. Combining the above results, we found that the AQP3 expression in the high c-Met expression group was significantly higher than that in the low c-Met expression group (61.2\% versus $10.0 \%)$, as shown in Table 4. Through correlation analysis, we found a positive correlation between AQP3 and c-Met expression $(r=0.385, p=0.003)$.

\section{2. c-Met regulates AQP3 expression in breast cancer cells}

Different concentrations of hHGF were used to treat breast cells, and then we tested AQP3 expression. We discovered that hHGF treatment increased the AQP3 expression level in a dose-dependent manner. In addition, AQP3 protein expression was increased 1.6-5.0 times, and AQP3 mRNA expression was increased 1.8-4.4 times in MCF-7 cells by treatment with hHGF over a range of $5-50 \mathrm{ng} / \mathrm{ml}$. In addition, AQP3 protein expression was increased 1.4-4.2 times, and AQP3 mRNA expression was increased 2.511.7 times in MDA-MB-231 cells (Fig. 2). Additionally, to further confirm that c-Met regulates AQP3 expression, we transfected c-Met-specific siRNA into breast cell lines, thereby reducing c-Met expression, and then assessed the expression of AQP3. We found that when c-Met expression was reduced by c-Metspecific siRNA treatment, AQP3 expression was significantly reduced. After c-Met-specific siRNA transfection, c-Met mRNA expression decreased to $35.8 \%$, and AQP3 mRNA expression decreased to $23.5 \%$ in MCF-7 cells. In addition, c-Met mRNA expression decreased to $59.9 \%$, and AQP3 mRNA expression decreased to $18.5 \%$ in MDA-MB-231 cells (Fig. 3A). In addition, the c-Met protein expression level decreased to $36.6 \%$, and the AQP3 protein expression level decreased to $22.4 \%$ in MCF-7 cells. The expression level of the c-Met protein decreased to $59.2 \%$, and the AQP3 protein expression level decreased correspondingly to $32.2 \%$ in MDA-MB-231 cells (Fig. 3B). The above immunoblot and RT-qPCR results revealed that AQP3 expression could be regulated by c-Met in breast cancer cells.

\section{3. c-Met regulates human breast cancer cell migration by regulating AQP3 expression}


Previous studies have shown that increased AQP3 and c-Met expression increases the risk of tumour development and metastasis (14-16). Moreover, our findings showed that AQP3 expression could be regulated by c-Met in breast cancer cells. Therefore, to confirm that c-Met can promote migration by regulating AQP3 expression in breast cancer cells, we conducted further research. A wound scratch assay showed that hHGF notably promoted the migration of MCF-7 and MDA-MB-231 cells. Moreover, c-Metspecific siRNA and AQP3-specific siRNA significantly inhibited the migration of these cells induced by hHGF (Fig. 4).

\section{Discussion}

Breast cancer ranks first in incidence among female malignancies, and it is the leading cause of cancerrelated death in women (1). Therefore, understanding the mechanisms underlying the invasion, proliferation, and cell transfer of breast cancer and the discovery of new therapeutic molecular targets are extremely important. AQP3 and c-Met are overexpressed in various malignant tumours, such as breast cancer $(2,3,9,17)$. Here, our study demonstrated that AQP3 and c-Met were overexpressed in $52.5 \%$ and $83.1 \%$ of breast cancer tissue specimens, respectively. Studies to date have deeply explored the relationship between AQP3 and breast cancer. The correction between c-Met and breast cancer has also been thoroughly studied. Zhu ZC et al. (13) and Kim YJ et al. (18) indicated that both AQP3 overexpression and c-Met overexpression were positively correlated with some poor prognostic factors, such as an increased tumour size and lymph node involvement. However, there is no evidence of a relationship between AQP3 and c-Met in breast cancer. Our study discovered that AQP3 expression was significantly higher in the high c-Met expression group, and that the overexpression of AQP3 and c-Met was positively correlated with tumour size and PTNM stage. Through correlation analysis, we found a positive correlation between AQP3 and c-Met expression.

Cao XC et al. (12) indicated that the activation of PI3K and/or ERK can promote AQP3 expression. In addition, a study by S Garcia et al. $(4,5)$ showed that the activation of c-Met led to phosphorylation of downstream proteins (mainly gab1, followed by gab2) and subsequent activation of signal transduction proteins such as PI3K and ERK. However, the upstream pathway of AQP3 and the downstream pathway of c-Met have not been studied. We postulated that c-Met may induce AQP3 expression to perform its biological function. In this study, we first revealed that hHGF upregulated AQP3 expression in a dosedependent manner, while c-Met-specific siRNA significantly attenuated AQP3 expression. Huang YT et al. (11) and Hiscox S et al. (19) showed that overexpression of AQP3 and c-Met strongly enhanced the migration and invasion of human breast cancer cells. Our research established that hHGF promotes the migration of breast cancer cells, while c-Met-specific and AQP3-specific siRNAs inhibited migration, and hHGF significantly reduced the effect of AQP3-specific and c-Met-specific siRNAs. These results revealed that AQP3 has a unique status in the c-Met-induced migration of human breast cancer cells, which also means that c-Met is likely to regulate the biological behaviour of human breast cancer by regulating AQP3 expression. 
This study did have limitations. There may have been a selection bias when the inclusion criteria were formulated. We noticed that c-Met overexpression was closely associated with an advanced pTNM stage and increased tumour size and that AQP3 overexpression showed significant positive correlations with age, tumour size, and lymph node invasion, which were different from the correlations found in other studies. This may be due to the comparatively small group size of the samples and the process used for selection of patient samples. To elucidate which factors are related to the overexpression of AQP3/c-Met in breast cancer, we still need studies with larger sample sizes. To better understand how c-Met upregulates AQP3 expression in breast cancer, further mechanistic research is needed. In future research, we may conduct in-depth research on the ERK and/or PI3K signalling pathways.

\section{Conclusions}

In conclusion, our results suggest that AQP3 plays an essential role in c-Met-mediated tumour metastasis and invasion in human breast cancer. These findings illustrate the essential role of AQP3 in breast cancer and further the understanding of the molecular mechanism underlying the role of c-Met in breast cancer cells, which may provide another possible approach for targeted treatment of breast cancer.

\section{Abbreviations}

American Joint Committee on Cancer (AJCC), analysis of variance (ANOVA), aquaporins (AQP), aquaporin 3 (AQP3), cellular-mesenchymal to epithelial transition factor (c-Met), enhanced chemiluminescence (ECL), hepatocyte growth factor (HGF), human hepatocyte growth factor (hHGF), negative control (NC), phenylmethanesulfonyl fluoride (PMSF), polyvinylidene fluoride (PVDF), radioimmune precipitation assay (RIPA), quantitative real-time polymerase chain reaction (RT-qPCR), silencing small interfering RNA (siRNA), standard error (SE).

\section{Declarations}

\section{Ethics approval and consent to participate}

This study was approved by the Ethics Committee of Taizhou Hospital of Zhejiang Province. All patients involved provided written informed consent for the publication of this study.

\section{Consent for publication}

Written informed consent for publication was obtained from all patients involved.

\section{Availability of data and materials}

All data generated or analyzed during this study are included in this published article.

\section{Competing interests}


The authors declare that they have no competing interests.

\section{Funding}

Not applicable.

\section{Authors' contributions}

FZ and FC were responsible for experimental design and manuscript preparation. $L C$ and $Y Z$ performed the experiments with the assistance of FZ. ZW performed the data acquisition and analysis. All authors read and approved the final manuscript.

\section{Acknowledgements}

The authors would like to thank all members of the study team and the patients.

\section{References}

1. Bray F, Ferlay J, Soerjomataram I, Siegel RL, Torre LA, Jemal A. Global cancer statistics 2018 : GLOBOCAN estimates of incidence and mortality worldwide for 36 cancers in 185 countries. CA Cancer J Clin. 2018;68(6):394-424.

2. Noriega-Guerra H, Freitas VM. Extracellular Matrix Influencing HGF/c-MET Signaling Pathway: Impact on Cancer Progression. Int J Mol Sci. 2018;19(11).

3. Ghoussoub RA, Dillon DA, D'Aquila T, Rimm EB, Fearon ER, Rimm DL. Expression of c-met is a strong independent prognostic factor in breast carcinoma. Cancer. 1998;82(8):1513-20.

4. Garcia S, Dales JP, Charafe-Jauffret E, Carpentier-Meunier S, Andrac-Meyer L, Jacquemier J, et al. Overexpression of c-Met and of the transducers PI3K, FAK and JAK in breast carcinomas correlates with shorter survival and neoangiogenesis. Int J Oncol. 2007;31(1):49-58.

5. Furge KA, Zhang YW, Vande Woude GF. Met receptor tyrosine kinase: enhanced signaling through adapter proteins. Oncogene. 2000;19(49):5582-9.

6. Trusolino L, Bertotti A, Comoglio PM. MET signalling: principles and functions in development, organ regeneration and cancer. Nat Rev Mol Cell Biol. 2010;11(12):834-48.

7. Gherardi E, Birchmeier W, Birchmeier C, Vande Woude G. Targeting MET in cancer: rationale and progress. Nat Rev Cancer. 2012;12(2):89-103.

8. Walz T, Fujiyoshi Y, Engel A. The AQP structure and functional implications. Handb Exp Pharmacol. 2009(190):31-56.

9. Marlar S, Jensen HH, Login FH, Nejsum LN. Aquaporin-3 in Cancer. Int J Mol Sci. 2017;18(10).

10. Shi Z, Zhang T, Luo L, Zhao H, Cheng J, Xiang J, et al. Aquaporins in human breast cancer: identification and involvement in carcinogenesis of breast cancer. J Surg Oncol. 2012;106(3):26772. 
11. Huang YT, Zhou J, Shi S, Xu HY, Qu F, Zhang D, et al. Identification of Estrogen Response Element in Aquaporin-3 Gene that Mediates Estrogen-induced Cell Migration and Invasion in Estrogen Receptorpositive Breast Cancer. Sci Rep. 2015;5:12484.

12. Cao XC, Zhang WR, Cao WF, Liu BW, Zhang F, Zhao HM, et al. Aquaporin3 is required for FGF-2induced migration of human breast cancers. PLoS One. 2013;8(2):e56735.

13. Zhu Z, Jiao L, Li T, Wang H, Wei W, Qian H. Expression of AQP3 and AQP5 as a prognostic marker in triple-negative breast cancer. Oncol Lett. 2018;16(2):2661-7.

14. Satooka H, Hara-Chikuma M. Aquaporin-3 Controls Breast Cancer Cell Migration by Regulating Hydrogen Peroxide Transport and Its Downstream Cell Signaling. Mol Cell Biol. 2016;36(7):1206-18.

15. Arif M, Kitchen P, Conner MT, Hill EJ, Nagel D, Bill RM, et al. Downregulation of aquaporin 3 inhibits cellular proliferation, migration and invasion in the MDA-MB-231 breast cancer cell line. Oncol Lett. 2018;16(1):713-20.

16. <1997EXPRESSION OF THE c-MetHGF RECEPTOR IN HUMAN BREAST CARCINOMA.pdf>.

17. Jin L, Fuchs A, Schnitt SJ, Yao Y, Joseph A, Lamszus K, et al. Expression of scatter factor and c-met receptor in benign and malignant breast tissue. Cancer. 1997;79(4):749-60.

18. Kim YJ, Choi JS, Seo J, Song JY, Lee SE, Kwon MJ, et al. MET is a potential target for use in combination therapy with EGFR inhibition in triple-negative/basal-like breast cancer. Int $\mathrm{J}$ Cancer. 2014;134(10):2424-36.

19. Hiscox S, Parr C, Nakamura T, Matsumoto K, Mansel RE, Jiang WG. Inhibition of HGF/SF-induced breast cancer cell motility and invasion by the HGF/SF variant, NK4. Breast Cancer Res Treat. 2000;59(3):245-54.

\section{Tables}

Table 1 siRNA sequences

\begin{tabular}{ll}
\hline siRNA & siRNA sequences (5'-3') \\
\hline C-Met siRNA & $\begin{array}{l}\text { sense: GUCCCGAGAAUGGUCAUAATT } \\
\text { antisense: UUAUGACCAUUCUCGGGACTT }\end{array}$ \\
AQP3 siRNA & $\begin{array}{l}\text { sense: GGACGUGUUUCUGUCAUAATT } \\
\text { antisense: UUAUGACAGAAACACGUCCTT }\end{array}$ \\
NC siRNA & $\begin{array}{l}\text { sense: UUCUCCGAACGUGUCACGUTT } \\
\text { antisense: ACGUGACACGUUCGGAGATT }\end{array}$ \\
\hline
\end{tabular}

Table 2 Primer sequences 


\begin{tabular}{ll}
\hline Gene name & Primer sequences $\left(5^{\prime}-3^{\prime}\right)$ \\
\hline GAPDH & $\begin{array}{l}\text { Forward: AGCCTCAAGATCATCAGC } \\
\text { Reverse: GAGTCCTTCCACGATACC }\end{array}$ \\
c-Met & $\begin{array}{l}\text { Forward: CAGGCAGTGCAGCATGTAGT } \\
\text { Reverse: GATGATTCCCTCGGTCAGAA }\end{array}$ \\
NC siRNA & $\begin{array}{l}\text { Forward: CACAGCCGGCATCTTTGCTA } \\
\text { Reverse: TGGCCAGCACACACACGATA }\end{array}$ \\
\hline
\end{tabular}

Table 3 Expression of AQP3 and c-Met proteins in breast cancer tissues 


\begin{tabular}{|c|c|c|c|c|c|c|c|}
\hline \multirow[t]{2}{*}{ Clinicopathological features } & \multirow[t]{2}{*}{$\mathrm{N}=59$} & \multicolumn{2}{|c|}{ AQP3 expression n (\%) } & \multirow[t]{2}{*}{$p$} & \multicolumn{2}{|c|}{ c-Met expression n (\%) } & \multirow[t]{2}{*}{$p$} \\
\hline & & low (28) & $\operatorname{high}(31)$ & & low (10) & $\operatorname{high}(49)$ & \\
\hline \multicolumn{8}{|l|}{ Age $\llbracket$ years $\square$} \\
\hline$\leq 50$ & 32 & $19(59.4)$ & 13(40.6) & 0.046 & $5(15.6)$ & $27(77.1)$ & 0.768 \\
\hline$>50$ & 27 & $9(33.3)$ & 18(66.7) & & $5(18.5)$ & $22(81.5)$ & \\
\hline \multicolumn{8}{|l|}{ Menopausal status } \\
\hline Pre-menopause & 39 & $20(51.3)$ & 19(38.7) & 0.411 & $6(15.4)$ & $33(84.6)$ & 0.655 \\
\hline Post-menopause & 20 & $8(40.0)$ & $12(60.0)$ & & $4(20.0)$ & 16(80.0) & \\
\hline \multicolumn{8}{|l|}{ Surgery } \\
\hline Mastectomy & 21 & $8(38.1)$ & 13(61.9) & 0.284 & $2(9.5)$ & 19(90.5) & 0.258 \\
\hline Breast conserving & 38 & $20(55.3)$ & $18(44.7)$ & & $8(21.1)$ & $30(78.9)$ & \\
\hline \multicolumn{8}{|l|}{ Histological grade } \\
\hline प- II & 35 & $17(48.6)$ & $18(51.4)$ & 0.836 & $7(20.0)$ & $28(80.0)$ & 0.451 \\
\hline III & 24 & 11(45.8) & $13(54.2)$ & & $2(8.7)$ & $21(91.3)$ & \\
\hline \multicolumn{8}{|l|}{ Tumor size } \\
\hline$\leq 2 \mathrm{~cm}$ & 22 & 15(68.2) & $7(31.9)$ & 0.014 & $8(36.4)$ & 14(63.6) & 0.002 \\
\hline$\square 2 \mathrm{~cm}$ & 37 & $13(35.1)$ & $24(64.9)$ & & $2(5.4)$ & $35(94.6)$ & \\
\hline \multicolumn{8}{|l|}{ Nodal status } \\
\hline Negative & 30 & 18(60.0) & $12(40.0)$ & 0.0497 & $7(23.3)$ & 23(76.7) & 0.184 \\
\hline Positive & 29 & $10(34.5)$ & 19(65.5) & & $3(10.3)$ & 26(89.7) & \\
\hline \multicolumn{8}{|l|}{ TNM stage } \\
\hline I & 13 & $10(76.9)$ & $3(23.1)$ & 0.009 & $7(53.8)$ & $6(46.2)$ & 0.000 \\
\hline II & 37 & $17(45.9)$ & $20(54.1)$ & & $3(8.1)$ & $34(91.9)$ & \\
\hline III & 9 & 1(11.1) & 8(88.9) & & $0(0)$ & $9(100.0)$ & \\
\hline \multicolumn{8}{|l|}{ Ki-67 level } \\
\hline Low expression & 11 & $4(36.4)$ & 7(63.6) & 0.414 & $2(18.2)$ & $9(81.8)$ & 0.904 \\
\hline High expression & 48 & $24(50.0)$ & $24(50.0)$ & & $8(16.7)$ & $40(83.3)$ & \\
\hline \multicolumn{8}{|l|}{ ER station } \\
\hline Negative & 14 & $9(64.3)$ & $5(35.7)$ & 0.149 & $3(21.4)$ & 11(78.6) & 0.609 \\
\hline Positive & 45 & $19(38.5)$ & $26(57.8)$ & & $7(15.6)$ & $38(84.4)$ & \\
\hline \multicolumn{8}{|l|}{ PR station } \\
\hline Negative & 20 & $13(65.0)$ & $7(35.0)$ & 0.053 & $5(25.0)$ & $15(75.0)$ & 0.238 \\
\hline Positive & 39 & $15(43.5)$ & $24(61.5)$ & & $5(12.8)$ & $34(7.2)$ & \\
\hline \multicolumn{8}{|l|}{ HER-2 station } \\
\hline Negative & 41 & $19(46.3)$ & $22(53.7)$ & 0.796 & $7(17.1)$ & $34(82.9)$ & 0.969 \\
\hline Positive & 18 & $9(50.0)$ & $9(50.0)$ & & $3(16.7)$ & 15(83.3) & \\
\hline \multicolumn{8}{|l|}{ EGFR station } \\
\hline Negative & 44 & 17(38.6) & $27(62.4)$ & 0.020 & $12(27.3)$ & $32(72.7)$ & 0.165 \\
\hline Positive & 15 & 11(73.3) & $4(26.7)$ & & $7(46.7)$ & $8(53.3)$ & \\
\hline
\end{tabular}

Ki67 $\square 14=$ low expression $\square$ Ki67 $\geq 14=$ high expression. 


\begin{tabular}{|c|c|c|c|c|}
\hline & \multirow[b]{2}{*}{ Expression } & \multicolumn{2}{|c|}{ AQP3 } & \multirow[t]{2}{*}{$p$} \\
\hline & & $\operatorname{low}(\mathrm{n})$ & high(n) & \\
\hline \multirow[t]{2}{*}{ c-Met } & low & 9 & 1 & 0.003 \\
\hline & high & 19 & 30 & \\
\hline
\end{tabular}

\section{Figures}
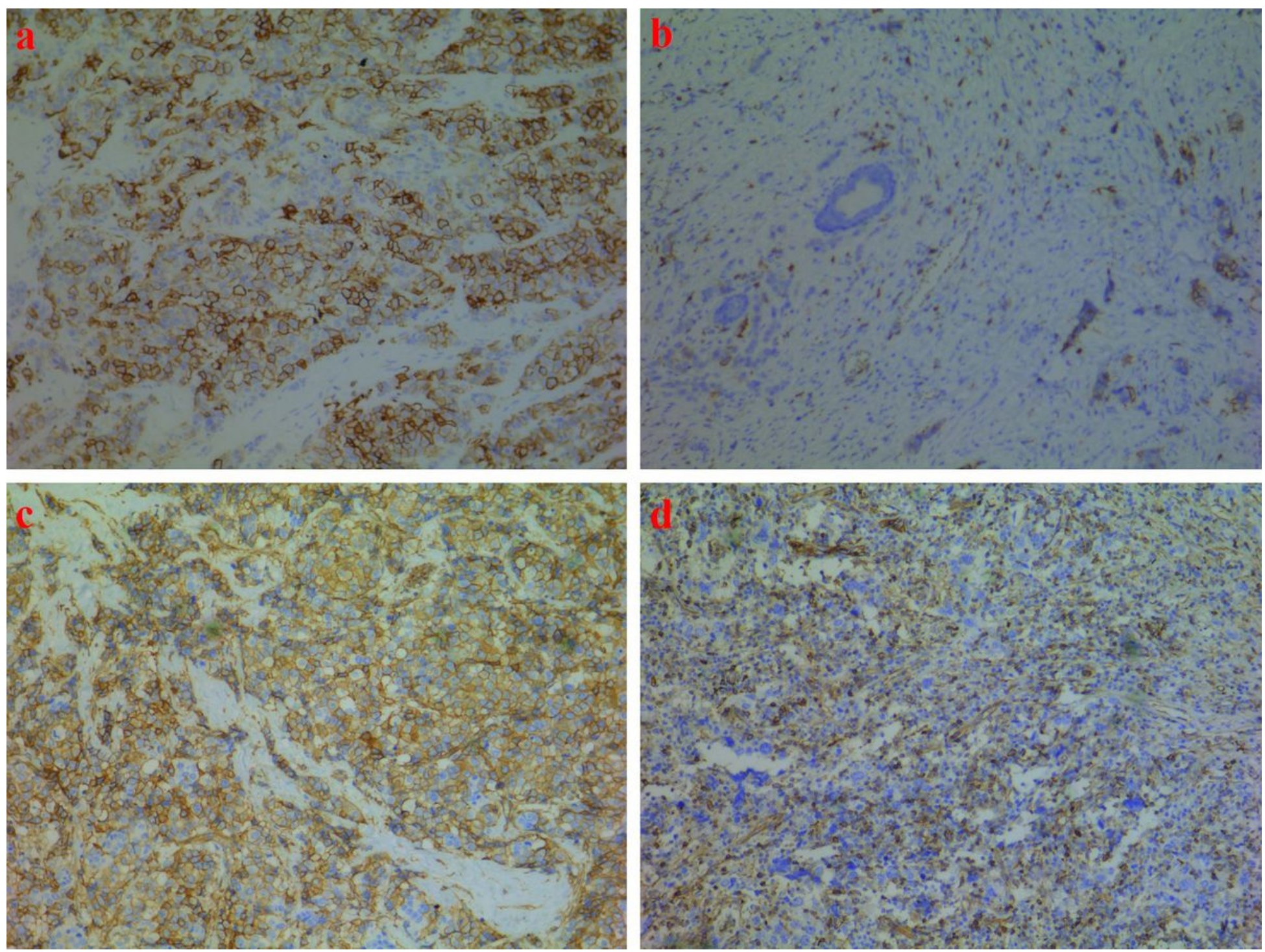

\section{Figure 1}

The expression of the AQP3 and c-Met proteins in breast cancer determined by immunohistochemistry. High expression and low expression of AQP3 were identified by assessing immunoreactivity as shown in $a$ and $b$, respectively. High expression and low expression of $c-M e t$ were identified by assessing immunoreactivity as shown in $c$ and d, respectively. Original magnification, 100x. 
A

MCF-7

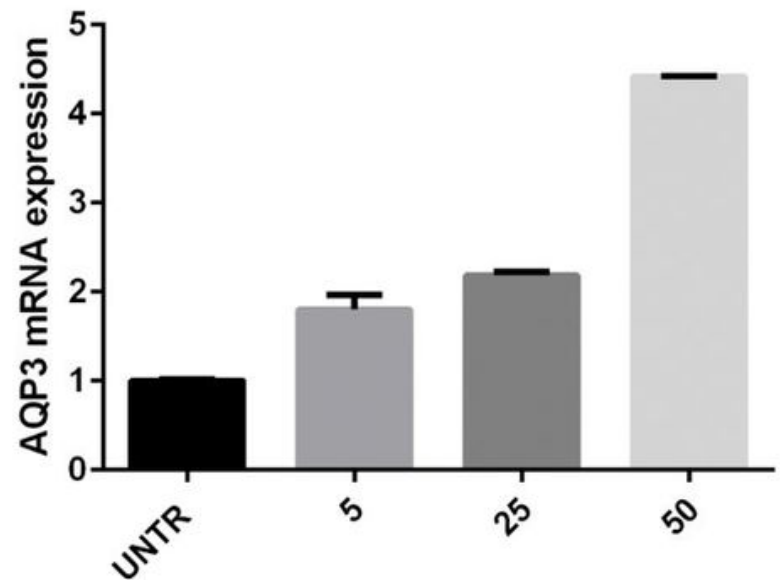

hHGF(ng/ml)

B



$\beta$-actin

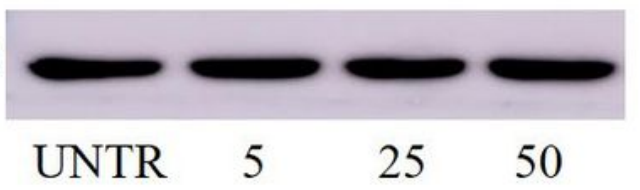

hHGF(ng/ml)

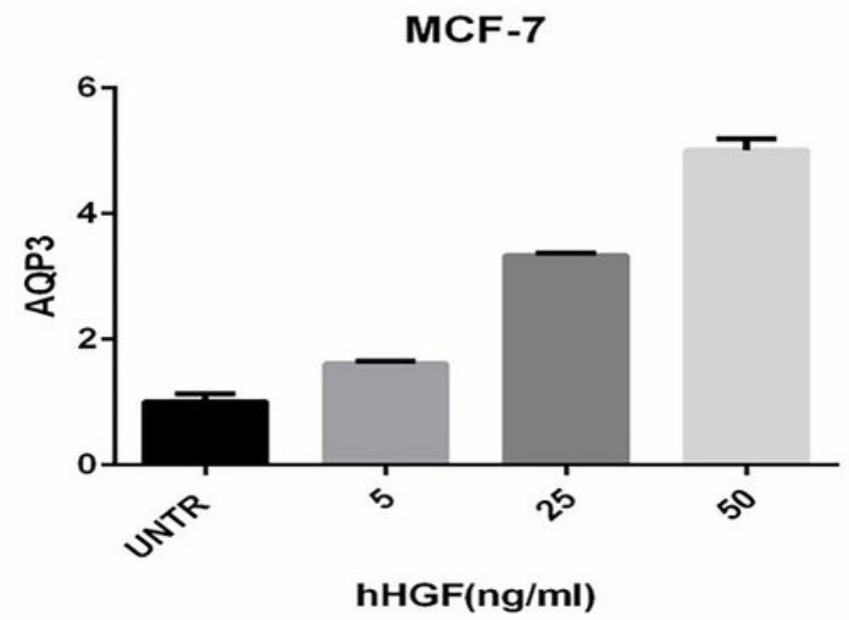

MDA-MB-231

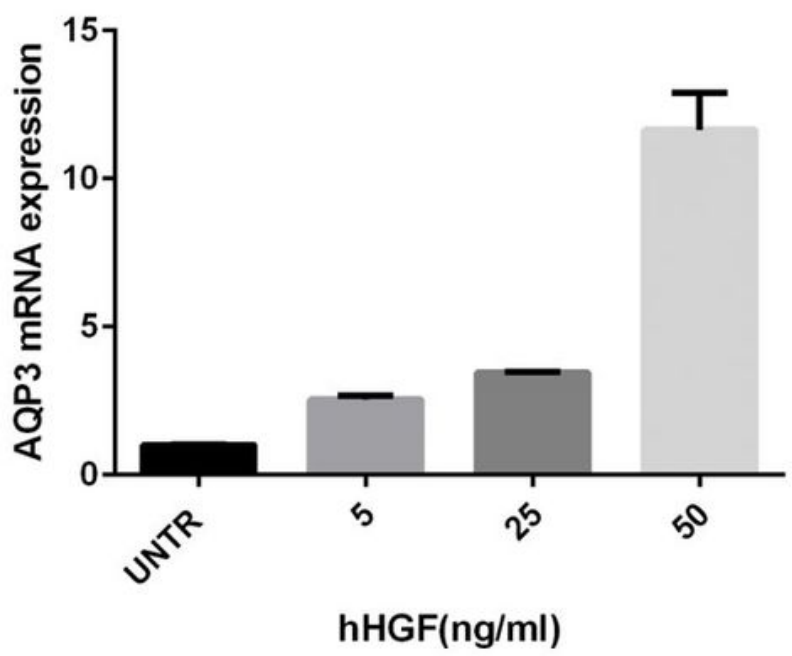

MDA-MB-231



MDA-MB-231

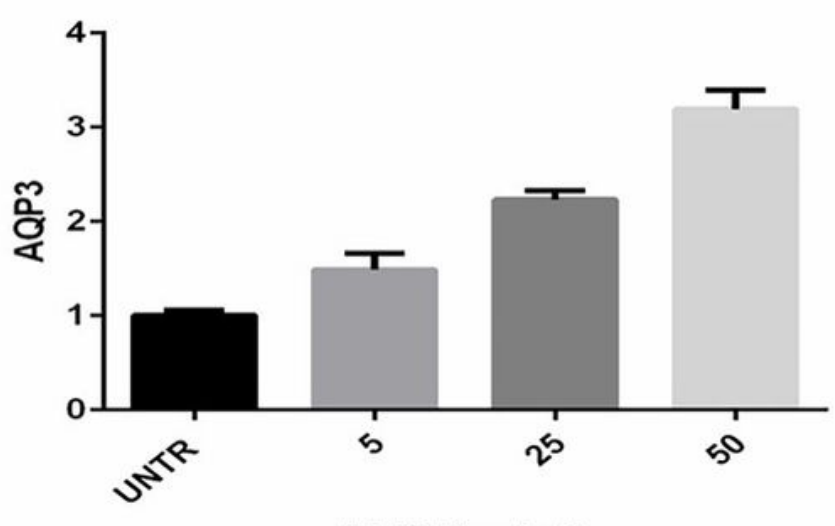

hHGF(ng/ml)

Figure 2

hHGF increases AQP3 expression in breast cancer cells. Cultured MCF-7 and MDA-231 cells were treated with different concentrations of $\operatorname{hHGF}(5,25$, or $50 \mathrm{ng} / \mathrm{mL})$, and then AQP3 mRNA expression was detected by RT-qPCR after 24 hours (A). AQP3 protein expression was detected by WB after 48 hours (B). $p<0.05$ versus the untreated (UNTR) group. 

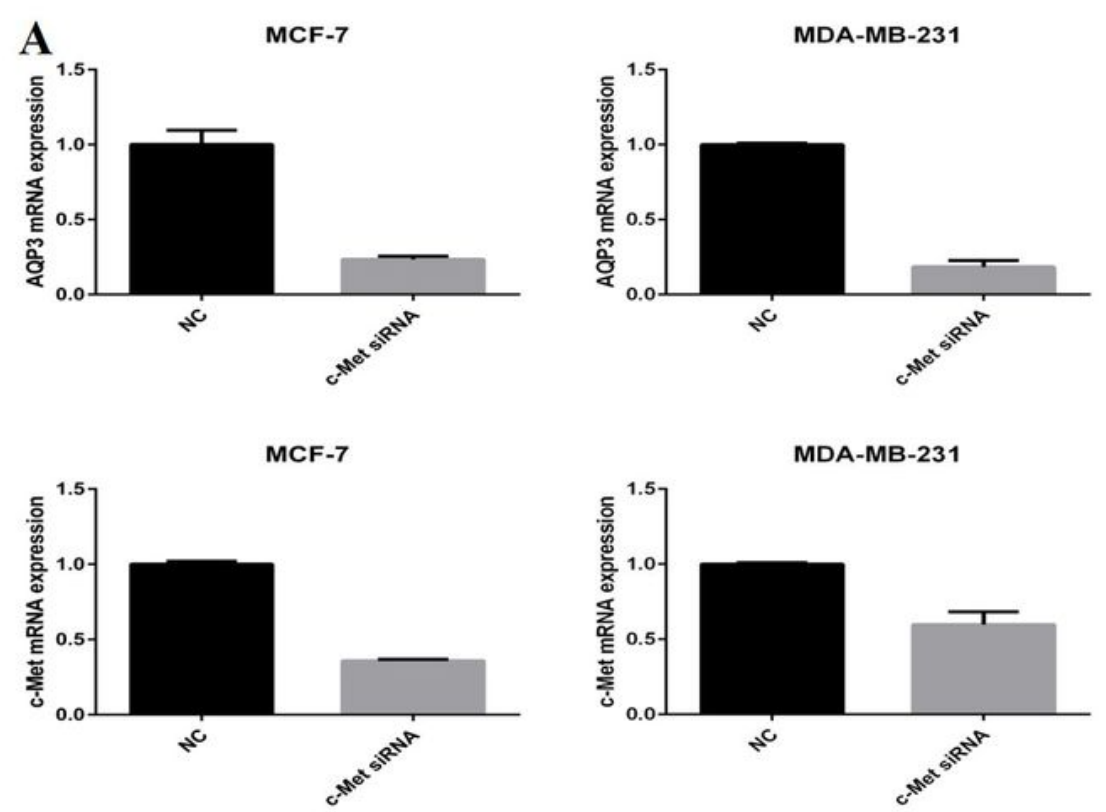

B

MCF-7



MDA-MB-231
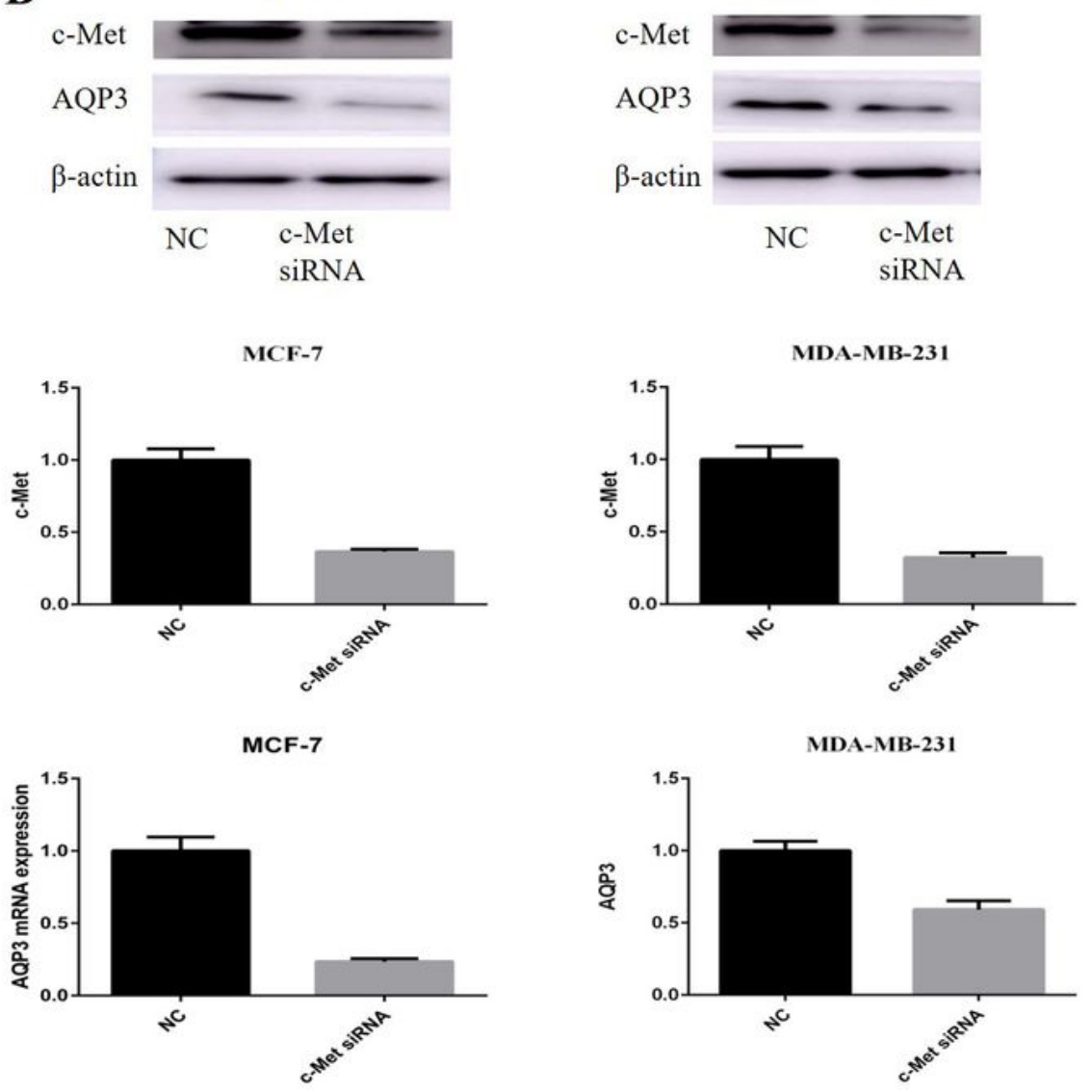

\section{Figure 3}

c-Met downregulation restrains AQP3 expression in breast cancer cells. After 48 hours of treatment of MCF-7 and MDA-231 cells with c-Met-specific siRNA or a negative control (NC), the c-Met-specific siRNA reduced the expression level of c-Met and correspondingly reduced AQP3 expression. AQP3 mRNA and protein expression was analysed by RT-qPCR and WB, respectively ( $A$ and $B$ ). $p<0.05$ versus NC. 
MCF-7
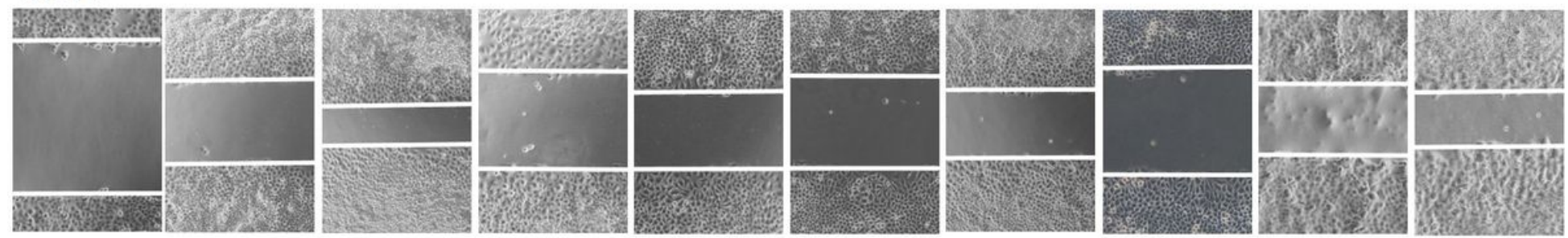

MDA-MB-231

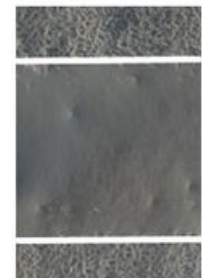

$\mathrm{Oh}$

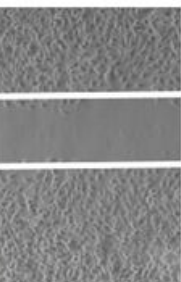

UNTR



hHGF
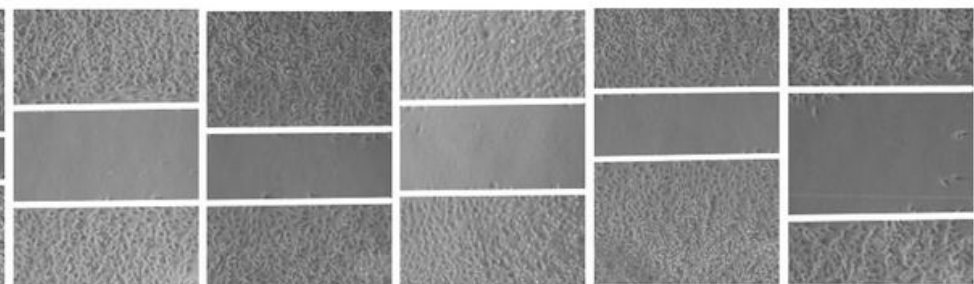

c-Met siRNA c-Met siRN
+ hHGF



NC

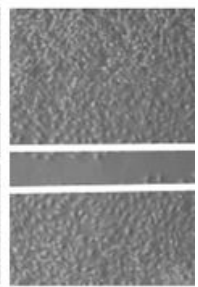

$\mathrm{NC}+\mathrm{hHGF}$
MCF-7

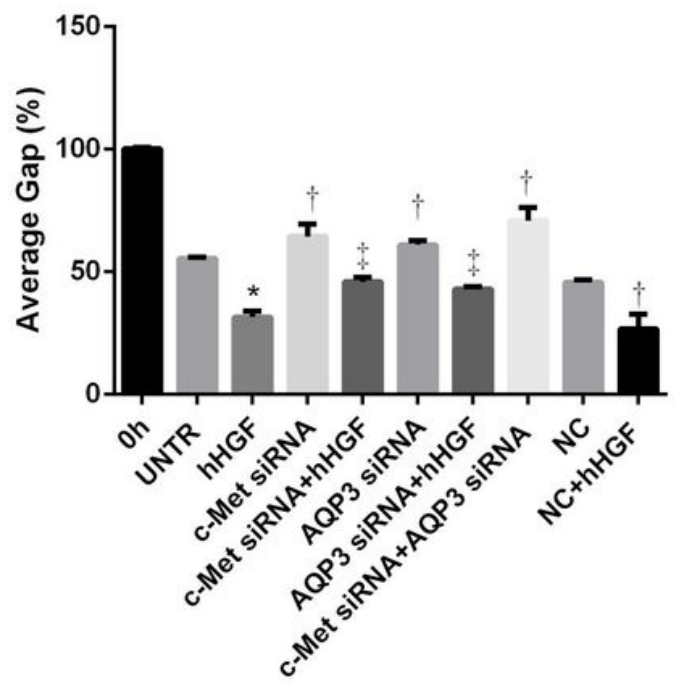

MDA-MB-231



\section{Figure 4}

c-Met regulates AQP3 to promote cell migration in breast cancer. A wound scratch assay was used to detect cell migration, and we imaged the results at 24 hours. The results are reported as the "average gap". ${ }^{*} p<0.05$ versus the NC+ hHGF-treated group. $\dagger p<0.05$ versus NC. $\neq p<0.05$ versus UNTR. 